\title{
Slow release of oxygen from carbamide peroxide for promoting the proliferation of human brain microvascular endothelial cells under hypoxia
}

\author{
Xiangrui Meng ${ }^{1,2 \#}$, Yuanyuan Sun ${ }^{2 \#}$, Lan Wang ${ }^{2 \#}$, Yuhao Li ${ }^{1}$, Ruizhuo Ouyang ${ }^{1}$, Ping Yuan ${ }^{2}$, Yuqing Miao ${ }^{1}$ \\ ${ }^{1}$ Institute of Bismuth Science, University of Shanghai for Science and Technology, Shanghai, China; ${ }^{2}$ Department of Cardio-Pulmonary Circulation, \\ Shanghai Pulmonary Hospital, Tongji University School of Medicine, Shanghai, China \\ Contributions: (I) Conception and design: X Meng, Y Sun, L Wang, P Yuan, Y Miao; (II) Administrative support: P Yuan, Y Miao; (III) Provision \\ of study materials or patients: Y Li, R Ouyang, P Yuan; (IV) Collection and assembly of data: X Meng, Y Sun, L Wang; (V) Data analysis and \\ interpretation: X Meng, Y Sun, L Wang, P Yuan; (VI) Manuscript writing: All authors; (VII) Final approval of manuscript: All authors. \\ \#These authors contributed equally to this work. \\ Correspondence to: Yuqing Miao. Institute of Bismuth Science, University of Shanghai for Science and Technology, Shanghai 200093, China. \\ Email: yqmiao@usst.edu.cn; Ping Yuan. Department of Cardio-Pulmonary Circulation, Shanghai Pulmonary Hospital, Tongji University School of \\ Medicine, Shanghai, China. Email: pandyyuan@tongji.edu.cn.
}

Background: Under hypoxic conditions, the brain can undergo irreversible damage. The present study aimed to explore new higher-oxygen-content carbamide peroxide (CP) compounds and the effect of their oxygen-releasing property on human brain microvascular endothelial cell (EC) proliferation under in vitro hypoxic conditions.

Methods: Two different additives including alpha-terpineol and sorbic acid were added to the reaction system to obtain the carbamide peroxide of CP-I and CP-II.

Results: We evaluated the oxygen generation capabilities of CP samples by using a portable dissolved oxygen meter. Consequently, alpha-terpineol as a stabilizer exhibited a unique effect on the oxygen generation of CP. CP-I was uniquely able to promote cell proliferation ability at $10 \mu \mathrm{g} \cdot \mathrm{L}^{-1}$ for hypoxic conditions, with the proliferation rates being $36.2 \%$ compared with the control group. The safety of CP to cells was further verified by calcein-AM/PI staining. Under hypoxic conditions, CP-I at $10 \mu \mathrm{g} \cdot \mathrm{L}^{-1} \mathrm{promoted}$ the migration rate, and the migration rate being $32.37 \%$.

Conclusions: These compounds have the advantages of simple synthesis, long storage time, low cost, and rich oxygen content. Used spectrophotometry, oxygen electrode test, and indicator titration for testing the oxygen production rate and oxygen production. The results indicate that alpha-terpineol is the best additive. CP-I exhibited the highest oxygen content and a superior effect on the cell phenotype than CP-II, especially under hypoxia. This study is the first to report the effects of CP on cells, and provides new therapeutic insights into cerebrovascular injury repair.

Keywords: Carbamide peroxide (CP); oxygen release; antihypoxia; cell proliferation; alpha-terpineol

Submitted Dec 02, 2020. Accepted for publication Jan 21, 2021.

doi: $10.21037 / \mathrm{atm}-20-8137$

View this article at: http://dx.doi.org/10.21037/atm-20-8137 


\section{Introduction}

Cerebral blood flow primarily serves to transport oxygenated blood through capillaries in the brain (1-4). In this process, oxygen and nutrients in the capillaries are transferred to local brain tissues, which maintains normal cognitive brain function (2-5). The endothelial cells (ECs) in the brain's capillaries are used to separate the blood from the brain parenchyma. In the cerebral capillaries, the monolayer endothelium is an important channel for the exchange of nutrients and metabolites between the blood and brain, and also functions as a barrier against blood neurotoxicity $(3,6)$. Because of the presence of crucial tight junction complexes and efflux transporters, these Ecs play a crucial role as doormen, regulating central nervous system homeostasis $(6,7)$. Brain microvessel endothelial cells (BMECs) are the cells of the cellular interface which function to separate the blood and its constituents from the brain extracellular fluid (6,8-10). BMECs are the tight junction between brain endothelial cells to form the intercellular barrier (11), and the major components of the blood-brain barrier $(8,11,12)$.

Hypoxia is a condition that can adversely impact a multitude of physiological processes, including cell proliferation, motility, apoptosis, angiogenesis, and erythropoiesis. For instance, in most cells, hypoxia can inhibit cell proliferation (13-15), and, with the increase of cell numbers, $\mathrm{O}_{2}$ consumption increases, leading to hypoxic stress $(4,16)$. It has been reported that hypoxia can cause structural anomalies and functional changes, and ultimately lead to cell death (17-19). Furthermore, hypoxia has adverse impacts on cell volume and the ion absorption of BMECs (12). Previous studies of the blood-brain barrier have identified the decrease in the number of capillaries as one of the main causes of apoptosis and clearance of BMECs $(8,20)$.

Carbamide peroxide (CP) is a hydrogen peroxide-like solid compound with high solubility in water. It is usually found in the form of a white powder of lamellar crystal (21-23). Its decomposition in water yields urea, hydrogen peroxide, oxygen, and some free radicals $(24,25)$. Therefore, $\mathrm{CP}$ has the properties of both hydrogen peroxide and urea (26). At low doses, it decomposes to produce oxygen at a lower toxicity, while at high doses, it has strong oxidation effects by producing reactive oxygen species (ROS) $(27,28)$. Here, we report the chemical synthesis of $\mathrm{CP}$ with different additives through a one-step reaction at room temperature and describe in detail the subsequently derived CP compounds. These compounds were used to treat our experimental model: human BMECs (HBMECs). The effects of the CP compounds on BMEC migration and proliferation were analyzed by scratch migration assays and cell counting kit-8 test kit (CCK-8), respectively. We present the following article in accordance with the MDAR reporting checklist (available at http://dx.doi.org/10.21037/ atm-20-8137).

\section{Method}

\section{Reagents}

Hydrogen peroxide $\left(\mathrm{H}_{2} \mathrm{O}_{2}, 30 \%\right)$ was purchased from Sinopharm Chemical Reagent Co., Ltd. (Shanghai, China). Urea, alpha-terpineol and sorbic acid were purchased from Aladdin Reagent Database Inc. (Shanghai, China). All chemicals were of analytical grade and used without further purification. The CCK-8 and Annexin-V-FITC/Propidium Iodide (PI) apoptosis detection kit were purchased from Dojindo (Shanghai, China).

\section{Synthesis of CP-I and CP-II}

Urea $(3.0 \mathrm{~g})$ was added into hydrogen peroxide of $2.5 \mathrm{~mL}$ and the mixture was stirred to dissolve. Then, $0.5 \mathrm{~mL}$ alphaterpineol and $0.05 \mathrm{~g}$ sorbic acid were added into the solution, to obtain the solutions of CP-I and CP-II respectively. After being stirred at room temperature for 40 minutes, the solution was cooled to $5{ }^{\circ} \mathrm{C}$ to crystallize for $24 \mathrm{~h}$. Then, the liquid was removed by filtering and by vacuum freezedrying for $24 \mathrm{~h}$. Finally, this yielded the solid forms of CP-I and CP-II.

\section{Instruments and methods}

The surface morphology of the samples was observed using a scanning electron microscope (SEM) (MIRA3 XMU/ XMH, TESCAN, Brno, Czech Republic). The crystal phase of the sample was identified using an Ultima IV X-ray diffractometer (XRD) (Rigaku Corporation, Japan). The Nicolet 380 (Thermo Fisher Scientific, USA) was used to characterize the Fourier transform infrared spectra (FTIR) of samples.

\section{Oxygen generation measurement of the CP samples}

Methylene blue (MB) solution $\left(0.15 \mathrm{mmol} \cdot \mathrm{L}^{-1}, 50 \mathrm{~mL}\right)$ with $10 \mathrm{~g} \cdot \mathrm{L}^{-1} \mathrm{CP}-\mathrm{I}$ was stirred and then kept at room 
temperature for $150 \mathrm{~min}$. The mixture $(3 \mathrm{~mL})$ was collected at $30 \mathrm{~min}$ intervals, and the degradation of the $\mathrm{MB}$ in the mixture was analyzed by measuring the absorbance peak at $660 \mathrm{~nm}$ with a UV-visible spectrophotometer (U-3900H Spectrophotometer, Hitachi, Tokyo, Japan).

The dissolved oxygen content of the CP samples was compared by measuring the $\mathrm{O}_{2}$ content with an oxygen probe (ST300D Portable Dissolved Oxygen Meter, OHAUS Corp., Parsippany, NJ, USA). Next, $50 \mathrm{mg}$ of CP-I and CP-II alpha-terpineol, CP, CB plus terpineol, urea, and $\mathrm{H}_{2} \mathrm{O}_{2}$ were respectively dissolved in $5 \mathrm{~mL}$ of $\mathrm{H}_{2} \mathrm{O}$. The $\mathrm{O}_{2}$ generation in solution was measured every $5 \mathrm{~s}$ using dissolved oxygen meter.

Then, $0.14 \mathrm{~g}$ of CP-I was added into $60 \mathrm{~mL}$ of distilled water and $15 \mathrm{~mL}$ of $6 \mathrm{M} \mathrm{H}_{2} \mathrm{SO}_{4}$. The $\mathrm{O}_{2}$ released from the CP-I was titrated with $0.02 \mathrm{~mol} \cdot \mathrm{L}^{-1}$ of $\mathrm{KMnO}_{4}$ and calculated as follows:

$$
\begin{aligned}
& 5 \mathrm{H}_{2} \mathrm{O}_{2}+2 \mathrm{MnO}_{4}^{2-}+6 \mathrm{H}^{+} \rightarrow 2 \mathrm{Mn}^{2+}+5 \mathrm{O}_{2} \uparrow+8 \mathrm{H}_{2} \mathrm{O} \\
& \omega=\frac{0.04 \mathrm{cV}}{\mathrm{m}} \times 100 \%
\end{aligned}
$$

where $\omega$ is the mass fractions of ROS in CP-I and CP-II, $c$ is the concentration $(\mathrm{M})$ of $\mathrm{KMnO}_{4}, \mathrm{~V}$ is the consumed volume (mL) of $\mathrm{KMnO}_{4}$ solution, and $\mathrm{m}$ is the mass $(\mathrm{g})$ of $\mathrm{CP}-\mathrm{I}$ and CP-II.

\section{Cell culture}

The human brain microvascular EC line was purchased from the Shanghai Institute of Biochemistry and Cell Biology. HBMECs were cultured at $37^{\circ} \mathrm{C}$. For the normoxic condition, the culture gas was air with $5 \% \mathrm{CO}_{2}$; for the hypoxic condition, the culture gas was $\mathrm{N}_{2}$ with $2 \% \mathrm{O}_{2}$ and $5 \%$ $\mathrm{CO}_{2}$. All cells were cultured in the endothelial cell medium (ECM) with $5 \%$ fetal bovine serum (FBS) for nutritional support and $1 \%$ penicillin-streptomycin for antibacterial effects in vitro.

\section{Proliferation assay}

Briefly, HBMECs were cultured with $1 \times 10^{4}$ cells/well on 96-well plates for $4 \mathrm{~h}$. Then, the different concentrations of the CP samples were added and cultured for $24 \mathrm{~h}$ at the normoxic and hypoxic conditions. Cell viability was measured by CCK-8 assays. Experiments were performed according to the manufacturer's instructions. Absorbance was measured at $450 \mathrm{~nm}$ using BioTek Instruments molecular devices (Thermo
Fisher Scientific, USA). Sterile water was used as a negative control. To reduce the randomness of the experiment, 6 tests were conducted for each concentration. A P value $<0.05$ indicated statistical significance.

\section{Calcein-AM/PI staining}

After seeding for $48 \mathrm{~h}$, the HBMECs were harvested, washed with phosphate-buffered saline (PBS), and resuspended in the ECM medium by adding 5\% FBS to obtain a density of $1 \times 10^{5}$ cells $/ \mathrm{mL}$. HBMECs were then cultured at $200 \mu \mathrm{L} /$ well on $24-$ well plates for $4 \mathrm{~h}$. Then, the different concentrations of the CP samples were added and cultured for $24 \mathrm{~h}$ under normoxic and hypoxic conditions. After the treatment, HBMECs were analyzed for fluorescence by calcein-AM/PI staining. Experiments were conducted according to the manufacturer's instructions. For each sample, $5 \mu \mathrm{L}(2 \mu \mathrm{M})$ of calcein-AM and $5 \mu \mathrm{L}(2 \mu \mathrm{M})$ of PI were added to the HBMECs and incubated for $30 \mathrm{~min}$ in an incubator $\left(37^{\circ} \mathrm{C}\right)$ in the dark. Then, the cells were analyzed using a fluorescence microscope. Sterile water was used as a negative control.

\section{Scratch test}

First, HBMECs were digested and suspended in ECM containing $5 \% \mathrm{FBS}$ at a density of $5 \times 10^{5}$ cells $/ \mathrm{mL}$. Horizontal black lines were drawn behind 24-well plates, and then the HBMECs were seeded onto these plates ( $200 \mu \mathrm{L} /$ well). When the cells reached a confluence of $80 \%$, they were maintained in a serum-free medium for $8 \mathrm{~h}$. In the cell layer, a line was drawn to line with a $10 \mu \mathrm{L}$ pipette tip. Cells were washed with PBS after removing the nutrient solution. Then, the plates were added to a premade nutrient solution with different concentrations of CP-I-III (300 $\mu \mathrm{L} /$ well). The wells were cultured for $24 \mathrm{~h}$ under normoxic and hypoxic condition. Cell migration (0 h, $24 \mathrm{~h})$ was observed under a light microscope. Each experiment was repeated in 3 wells. In the control group, cells were grown in ECM containing 5\% FBS.

\section{Statistical analysis}

All data were analyzed using the SPSS 21.0 statistical analysis software (IBM SPSS, Armonk, NY, USA). The data are expressed as the mean \pm standard deviation. $\mathrm{P}<0.05$ was considered to indicated a statistically significant difference. 


\section{Results}

Currently, the reported stabilizers of $\mathrm{CP}$ are inorganic salts, which can potentially introduce metal elements that do not exist in CP $(29,30)$. Thus, other methods are required that can effectively stabilize and use the properties of $\mathrm{CP}$ without introducing other elements, while more oxygen is produced. Alpha-terpineol $\left(\mathrm{C}_{10} \mathrm{H}_{18} \mathrm{O}\right)$ is usually used in medicine as a deodorant, while sorbic acid $\left(\mathrm{C}_{6} \mathrm{H}_{8} \mathrm{O}\right)$ is a food additive (31). Here, the two additives have the same elemental composition as CP. Therefore, these two stabilizers were added instead of inorganic salts, and two new CPs (CP-I and CP-II) were synthesized at room temperature. The process was conducted as follows: urea was added to a hydrogen peroxide solution under stirring, which took about 7 minutes. After dissolved, alphaterpineol and sorbic acid were respectively added, and the mixtures were finally freeze-dried to obtain white crystals of CPs. These two novel CP compounds have not shown any moisture absorption during the storage period of 6 months thus far, and moisture absorption typically occurs within 1 month. Clearly, the presence of alpha-terpineol and sorbic can enhance moisture resistance.

The digital photo of CP-I after crystallization is shown in Figure 1A, and the semitransparent and long flake crystals pictured were obtained in the experiment. Meanwhile, the CP-II crystals are shown in Figure S1 (Supporting Information). After grinding, the powder was obtained. The SEM images in Figure 1B,C show the CP-I crystals with an average diameter of about $10 \mu \mathrm{m}$.

Then, X-ray diffraction (XRD) and FTIR were used to characterize the structure of the synthesized CP samples. The XRD spectra (Figure 1D) of two samples showed sharp peaks with narrow band-width, indicating remarkable crystallinity. Compared with the standard spectrum of CP [Joint Committee on Powder Diffraction Standards (JCPDS) card no. 54-0322], the monitored peaks of CP-1 at $13.8^{\circ}, 23.4^{\circ}, 25.7^{\circ}, 27.5^{\circ}$, and $30.6^{\circ}$ were well matched with the peaks of $\mathrm{CP}$, which could be ascribed to the 020,111 , 200, 040, and 140 crystal faces, respectively. No additional mismatching peaks with the standard spectrum of $\mathrm{CP}$ were monitored, indicating the high purity of the synthesized CP-1. In CP-II, some additional peaks were observed. In comparison to the standard spectra of urea (JCPDS card no. 83-1436), these monitored peaks were well matched, indicating that the obtained CP-II was a mixture of CP and urea. By comparing the half-peak width of the XRD spectra of the CPs, the results showed that sorbic acid, as a stabilizer, could better decrease the conversion rate compared with alpha-terpineol.

The FTIR spectra of two samples in Figure $1 E$ is visible in the stretching vibration of $\mathrm{O}-\mathrm{H}$ at $3,458 \mathrm{~cm}^{-1}$, which is caused by the water and the hydrogen bond hydroxyl groups $(32,33)$. Bands at around 3,352 and $2,812 \mathrm{~cm}^{-1}$ are the stretching vibration of $\mathrm{N}-\mathrm{H}$ and the stretching vibration of $\mathrm{O}-\mathrm{H}$, respectively (33-35). In most chemical environments, the hydroxide radical does not exist alone (36). The hydroxide radical may be in the same plane, or it may appear between neighboring molecular crystals. The effect of hydrogen bonding is one of the reasons for the formation of crystals and band broadening $(34,36)$. The peaks center at a wavenumber of 1,660 and $1,625 \mathrm{~cm}^{-1}$, are broad, and have the highest absorbance, and it is the dominant peak in the entire spectrum. The peaks at 1,660 and $1,625 \mathrm{~cm}^{-1}$ show the amide linkage and the in-plane bending vibration of $\mathrm{N}-\mathrm{H}$ (37), which is a characteristic vibration of urea $(34,37)$. The peaks at 1,460 and $1,160 \mathrm{~cm}^{-1}$ show the stretching vibration of $\mathrm{C}-\mathrm{N}(38,39)$. Interestingly, the out-of-plane bending vibration of $\mathrm{N}-\mathrm{H}$ occur at $780 \mathrm{~cm}^{-1}$ (40). Overall, the CP samples were successfully synthesized.

Next, to evaluate the oxygenic properties of CP samples, we further used spectrophotometry, oxygen electrode test, and indicator titration. $\mathrm{MB}$ is an indicator of oxygen since its absorption at $660 \mathrm{~nm}$ can be quenched by oxygen. Thus, the absorbance detection of the peak at $660 \mathrm{~nm}$ could reflect the oxygen generation. When CP-I and MB were mixed, the absorption peak at $660 \mathrm{~nm}$ gradually weakened with the extension of time (Figure $2 A$ ), indicating that the generated oxygen from CP-I might interact with $\mathrm{MB}$ to weaken its absorption peak. When CP-II was incubated with MB, a similar phenomenon of the absorbance attenuation of MB occurred (Figure S2), but the degree of absorbance reduction was lower than that of CP-I. Figure $2 B$ displays the relationship between $\mathrm{C}_{\mathrm{r}} / \mathrm{C}_{0}$ and processing time (min) of the degradation of $\mathrm{MB}$, revealing the development of degradation speed over time. When the degradation time was $150 \mathrm{~min}$, the decolorization ratios of the $\mathrm{MB}$ were $71.8 \%$ and $38.1 \%$, corresponding to CP-I and CPII, respectively. There is a digital photo of CP-I in $\mathrm{H}_{2} \mathrm{O}$ with no Tyndall phenomenon (inset of Figure 2). This shows that CP-I is completely soluble in water but not in suspension. We can initially guess that the CP mixed with alpha-terpineol has an excellent ability to generate oxygen, while the kinetic curve (Figure $2 B$ ) indicates that the oxygen production rate of CP-I is faster than that of CP-II over a shorter period. 

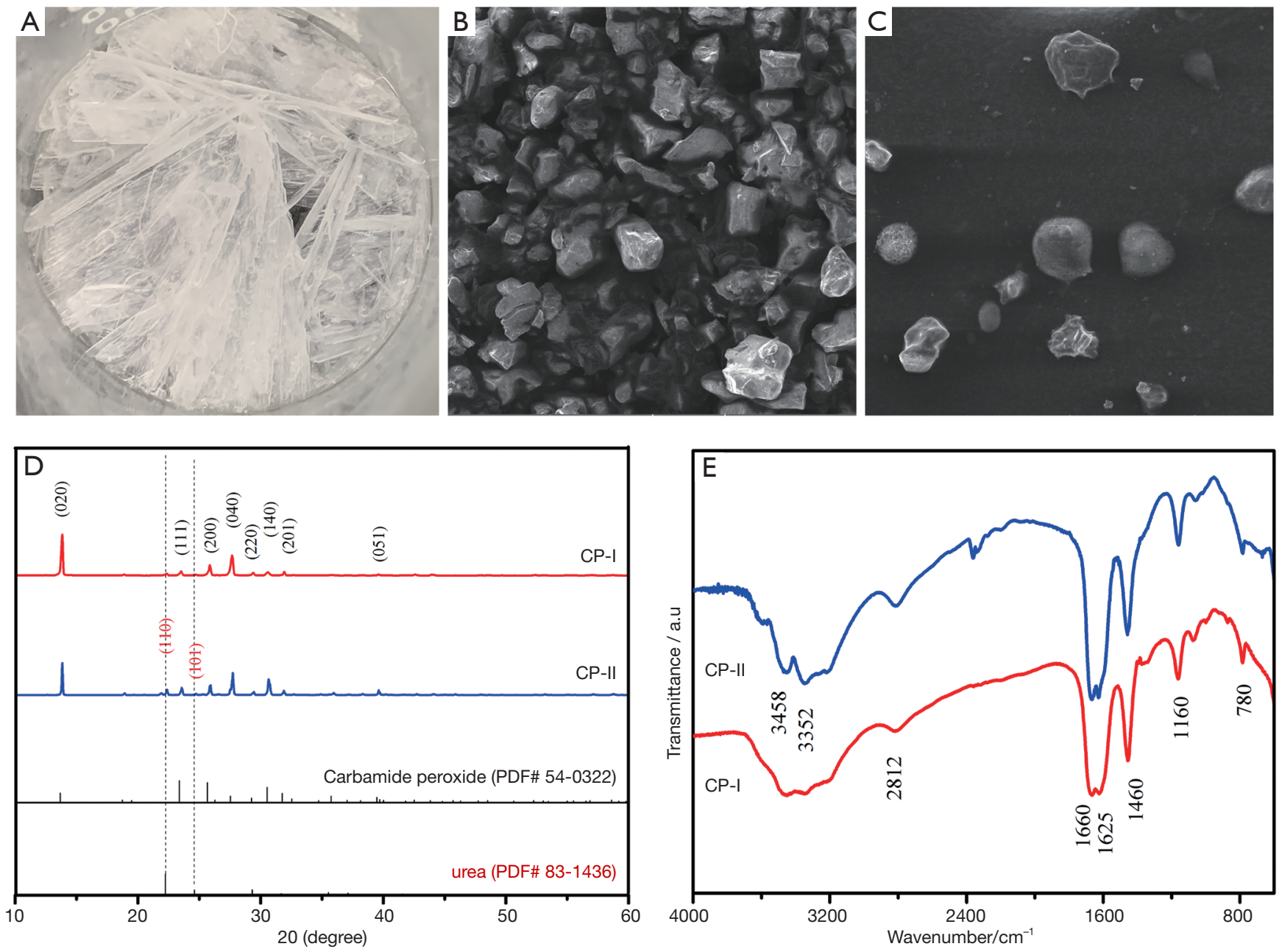

Figure 1 SEM, XRD and FTIR confirmed that CPs was successfully synthesized. Normal image of CP-I crystals (A) and image under SEM (B,C). XRD patterns (D) and FTIR spectra (E) of CP-I and CP-II. CP, carbamide peroxide; SEM, scanning electron microscope; XRD, X-ray diffractometer.

We further evaluated the oxygen generation capabilities of CP samples by using a portable dissolved oxygen meter $(41,42)$. To understand which parts could promote the oxygen generation, we set up several experimental control groups including $\mathrm{H}_{2} \mathrm{O}$, urea solution, $\mathrm{H}_{2} \mathrm{O}_{2}$ solution, $\mathrm{CP}$ solution, and $\mathrm{CP} / \mathrm{alpha}$-terpineol mixture solution (Figure $2 \mathrm{C}$ ). For $\mathrm{H}_{2} \mathrm{O}$ and urea solution groups, no oxygen generation was observed with the time extension. For the $\mathrm{H}_{2} \mathrm{O}_{2}$ solution, only weak oxygen generation was monitored. However, the rate of oxygen generation was fast. Furthermore, the CP solution also presented weak oxygen generation ability. Also, large amounts of oxygen were produced, and the oxygen production performance stabilized after $100 \mathrm{~s}$, indicating a high oxygen generation rate and performance of CP-I. Compared with CP-I, the oxygen generation ability of CP-II was lower. We attributed this decreased performance to the presence of stabilizers which induced a low content of CP in the CP-II. In addition, we explored the interaction between stabilizers and CP. When only alpha-terpineol and CP were mixed, no obvious oxygen generation was observed. This indicates that the formation of CP-I does not simply involve mixing alphaterpineol and CP, but rather other intermolecular actions could occur that promote crystallization, stabilization, and oxygen release. Consequently, alpha-terpineol as a stabilizer exhibited a unique effect on the oxygen generation of CP.

The oxygen production performance of CP samples was verified by potassium permanganate titration (Figure 2D), 

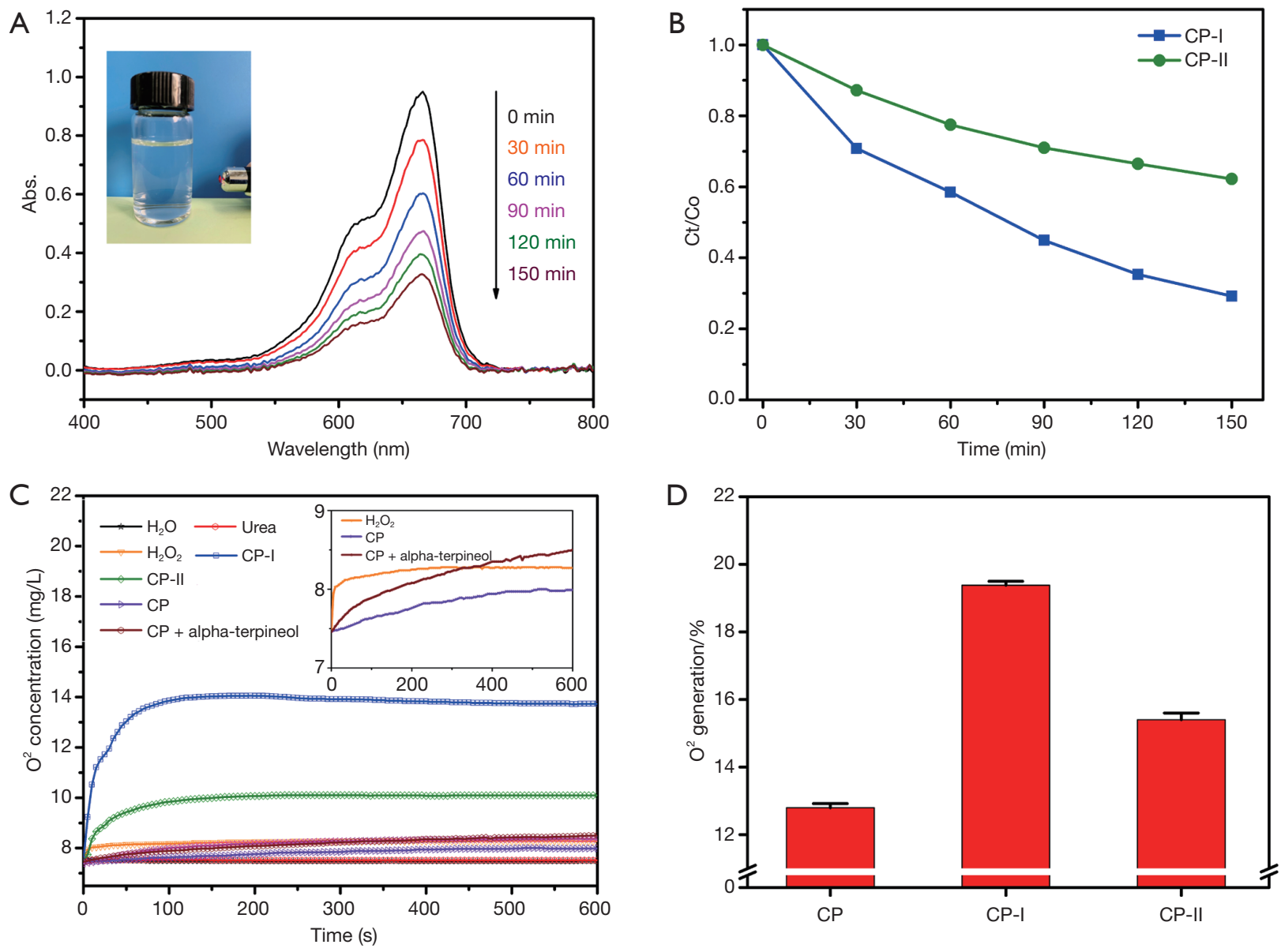

Figure 2 Three methods are used to detect the production and content of oxygen. (A) UV-vis absorption spectra of the CP-I solution $\left(10 \mathrm{mg} \cdot \mathrm{mL}^{-1}\right.$ ) containing $0.15 \mathrm{mmol} \cdot \mathrm{L}^{-1}$ methylene blue (inset is a digital photo of $\mathrm{CP}-\mathrm{I}$ in $\mathrm{H}_{2} \mathrm{O}$ which was irradiated with a red laser). (B) Measurement of MB degradation efficiencies in mixtures with CP-I samples. Measurement of dissolved oxygen content (C) and oxygen content (D) in the CP-I samples. CP, carbamide peroxide; MB, methylene blue.

which is a classic test for detecting the total amount of generated oxygen. The hydrogen peroxide in CP reacts with potassium permanganate to produce oxygen. The percentage of oxygen contained in the $\mathrm{CP}$ can be calculated by observing the color change of the solution. The oxygen content in CP, CP-I, and CP-II was $12.8 \%, 19.8 \%$, and $15.9 \%$, respectively. This result was consistent with the findings obtained from the two above-mentioned detection methods. Overall, the two oxygen detection methods proved that the additive significantly improved the rate and amount of oxygen production of CP. In particular, alphaterpineol as an additive has a unique promoting effect.

The effect of CP on HBMECs were studied in detail under normoxic and hypoxic conditions (Figure 3).

Previous studies have indicated that CP may cause cell apoptosis and death at high concentrations (43-45). CP is usually a double-edged sword: it can act as a kind of solid ROS to kill cells in high concentration, but it can also act as a solid oxygen release agent in low concentration to supply oxygen and promote the proliferation of cells (46-48). First, the cytotoxicity of CP-I and CP-II was evaluated, and the CCK- 8 was used to assess HBMECs' viability after the cells were treated with different concentrations of the two CPs for $24 \mathrm{~h}$. Under normoxic and hypoxic conditions, cytotoxicity was monitored under the concentration of CP-I higher than $10^{4} \mu \mathrm{g} \cdot \mathrm{L}^{-1}$, and the median lethal dose was $5 \times 10^{4} \mu \mathrm{g} \cdot \mathrm{L}^{-1}$. This indicated that CP-I possesses cytotoxicity under high concentrations (Figure 4A,B). Meanwhile, CP-II also demonstrated similar cytotoxicity under concentrations higher than $10^{4} \mu \mathrm{g} \cdot \mathrm{L}^{-1}$ (Figure S3). 


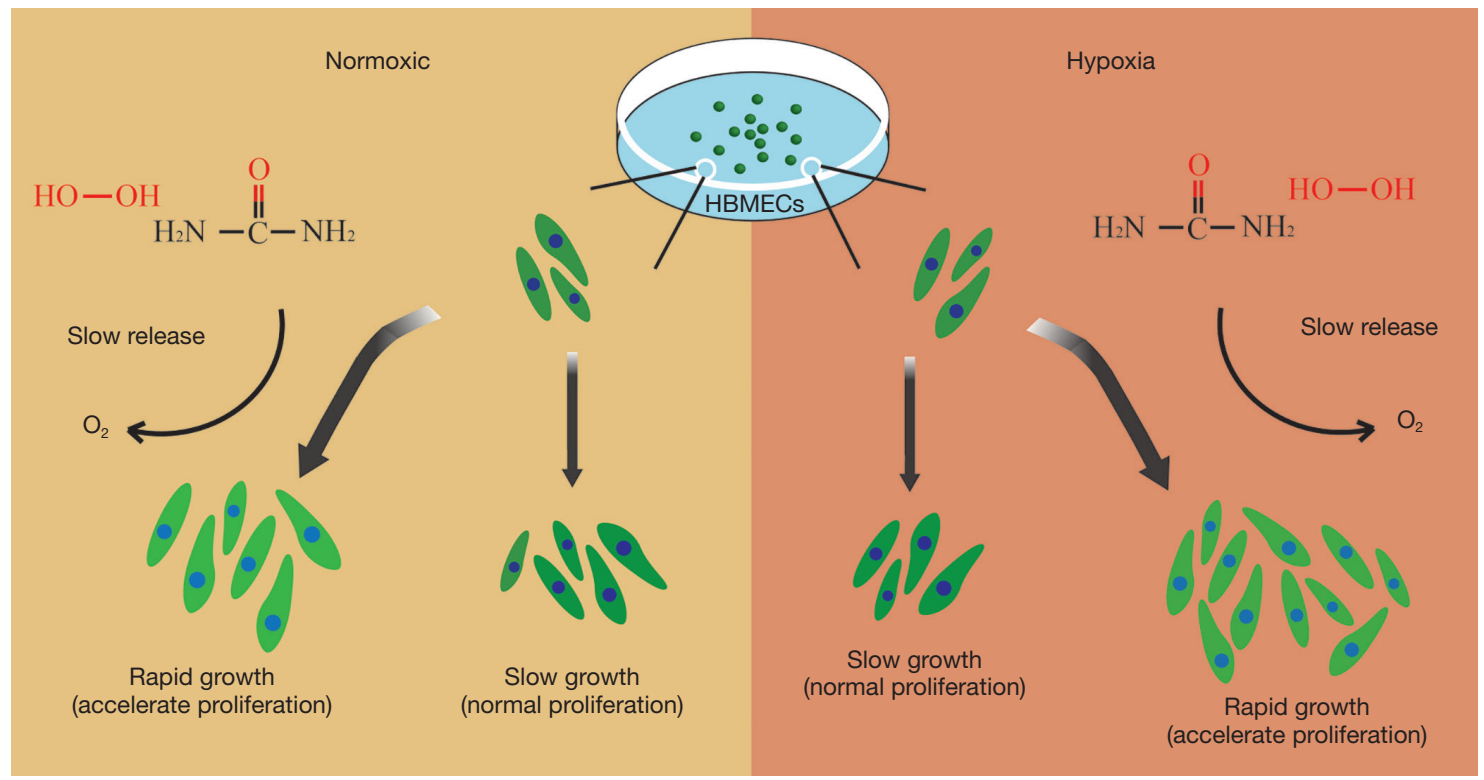

Figure 3 Illustration of the effect of carbamide peroxide on HBMECs under normoxic and hypoxic conditions. HBMECs, human brain microvessel endothelial cells.

Therefore, concentrations lower than $10^{4} \mu \mathrm{g} \cdot \mathrm{L}^{-1}$ were chosen to evaluate the effect of CP-I and CP-II on cell proliferation.

Next, HBMECs were treated with CP samples at the concentration range of $10^{-1}-10^{4} \mu \mathrm{g} \cdot \mathrm{L}^{-1}$ for $24 \mathrm{~h}$. The results showed that CP-I and CP-II significantly promoted the proliferation of HBMECs at this concentration range (Figure $4 C, D$ ) under both normoxic and hypoxic conditions. Compared with the control group, CP-I exhibited remarkable cell proliferation ability, which was superior to that of CP-II. These results were consistent with those gathered from the prior experiments (Figure 2). Notably, CP-I was uniquely able to promote cell proliferation ability at $10^{3}$ and $10 \mu \mathrm{g} \cdot \mathrm{L}^{-1}$ for normoxic and hypoxic conditions, with the proliferation rates being $21.8 \%$ and $36.2 \%$ compared with the control group, respectively. Meanwhile, for CP-II, the cell proliferation rates were $7.9 \%$ and $25.0 \%$ at a concentration of $10^{3}$ and $10^{2} \mu \mathrm{g} \cdot \mathrm{L}^{-1}$ under normoxic and hypoxic conditions, respectively. These results demonstrate that CP substantially improved the proliferation of HBMECs, especially under hypoxic conditions. We therefore speculated that CP may play a role in oxygen supply, providing energy for cell survival.

To further identify which components of the CP-I samples affected the cell proliferation viability of HBMECs, several control groups were incubated with HBMECs
(Figure $5 A, B$ ). For exploring CP-I, the control experiments were performed using the same concentrations of $\mathrm{H}_{2} \mathrm{O}_{2}$, urea, alpha-terpineol, and CP at normoxic and hypoxic conditions, respectively. Compared with all control groups, CP-I presented outstanding proliferation viability. At normal oxygen, the $\mathrm{H}_{2} \mathrm{O}_{2}$, CP, and urea groups demonstrated proliferation viability. However, the alpha-terpineol group effectuated no significant change. We speculate that the alpha-terpineol in CP-I has a synergistic effect with $\mathrm{CP}$, promoting the increase of oxygen storage and the continuous release of oxygen. Similarly, CP-II increased cell viability more than the control groups. Under hypoxic conditions, a similar proliferation effect was observed with CP-I showing the best proliferation ability. This also confirmed that alpha-terpineol and $\mathrm{CP}$ have a synergistic effect, in which CP generates more oxygen, ensuring cells survive in larger numbers under hypoxic conditions.

We then used calcein-AM/PI to stain live and dead cells to observe the state of the cells. Calcein-AM can penetrate the cell membrane, the AM group is removed by esterase action in living cells $(49,50)$, and the remaining calcein emits bright green fluorescence for living cell detection (51); meanwhile, PI can enter the dead cells through the damaged cell membrane, become embedded into the cell's DNA double helix structure, and produce red fluorescence, thereby making dead cells perceptible to 

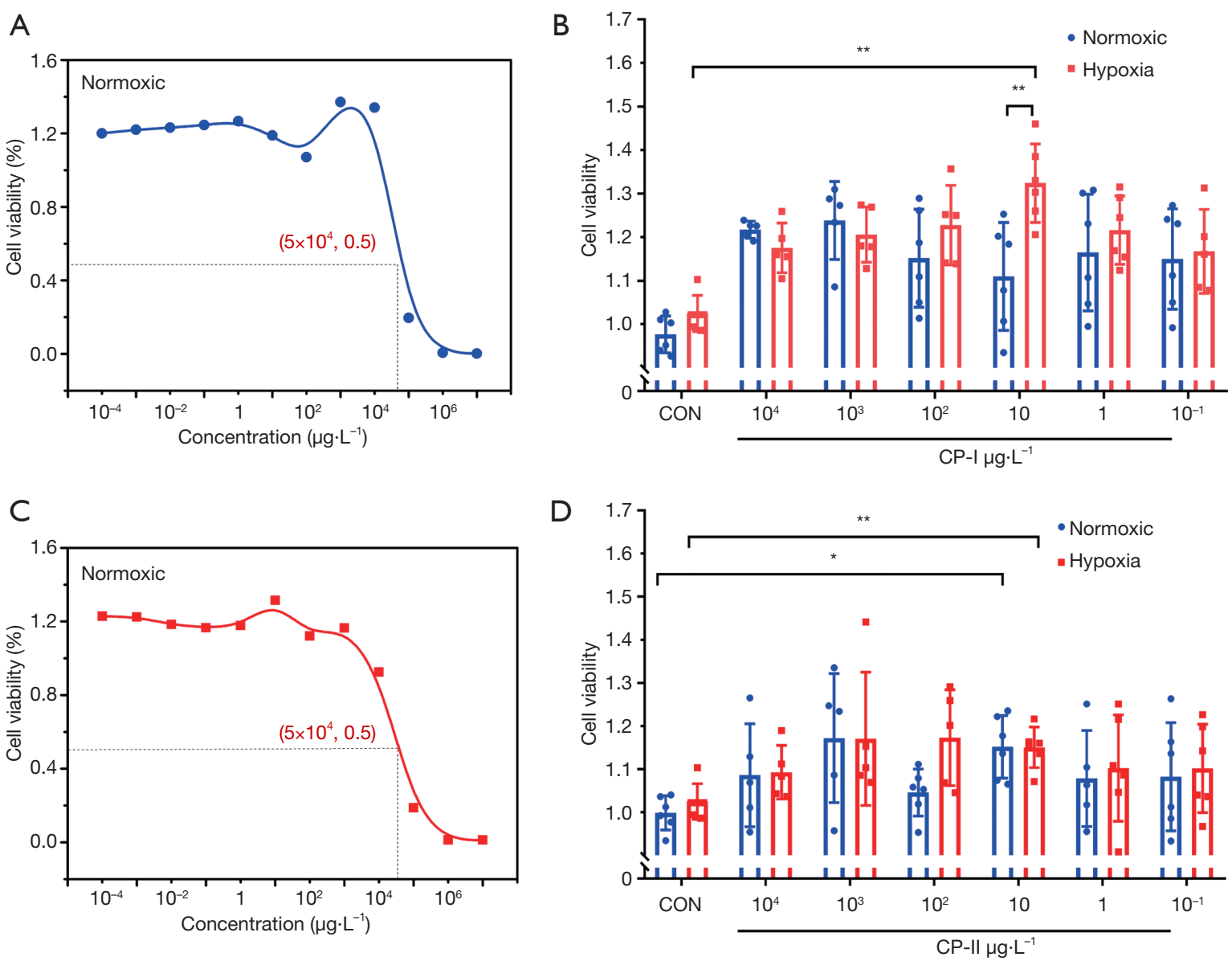

Figure 4 Cytotoxicity test of CP-I in normoxic (A) and hypoxic (B) conditions. Relative viabilities of HBMECs after incubation with different concentrations of CP-I (C) and CP-II (D) solution. * denotes $\mathrm{P}<0.05$ vs. control; ** denotes $\mathrm{P}<0.01$ vs. control; $\mathrm{n}=6$. CP, carbamide peroxide; HBMECs, human brain microvessel endothelial cells.

detection $(52,53)$. In Figure 6, HBMECs were treated with CP-I at different concentrations for $24 \mathrm{~h}$. Compared with the control group, no increased red fluorescence of PI was monitored, indicating outstanding biocompatibility at this concentration range. The green fluorescence of calcein was also observed, and the cell density increased at a higher concentration, confirming that CP-I could promote the proliferation of HBMECs.

Finally, the migration ability of cells after being treated with CP-I was examined.

Cell viability is generally related to cell migration ability. The scratch test was used to evaluate changes in HBMEC migration (Figure 7). The results indicated that CP-I effectively promoted the migration of HBMECs. Under normoxic conditions, the migration rate of cells treated with CP-I at $10 \mu \mathrm{g} \cdot \mathrm{L}^{-1}$ for $24 \mathrm{~h}$ increased by $28.23 \%$ compared to controls. Meanwhile, under hypoxic conditions, $24 \mathrm{~h}$ treatment of HBMECs with CP-I promoted the migration rate, and the migration rate of the $10 \mu \mathrm{g} \cdot \mathrm{L}^{-1}$ group increased by $32.37 \%$ compared with the control group. Interestingly, the cells in the hypoxic groups had a more positive migration ability than those in the normoxic groups. This can be attributed to the slow release of oxygen of CPI, which promoted cell activity. We therefore concluded that the CP with alpha-terpineol additive can be used as an oxygen supplier to increase the survival rate and migration ability of cells under hypoxia.

\section{Conclusions}

Two carbonamide peroxide (CP) compounds, CP-I and CPII, were developed, and their ability to increase the survival 

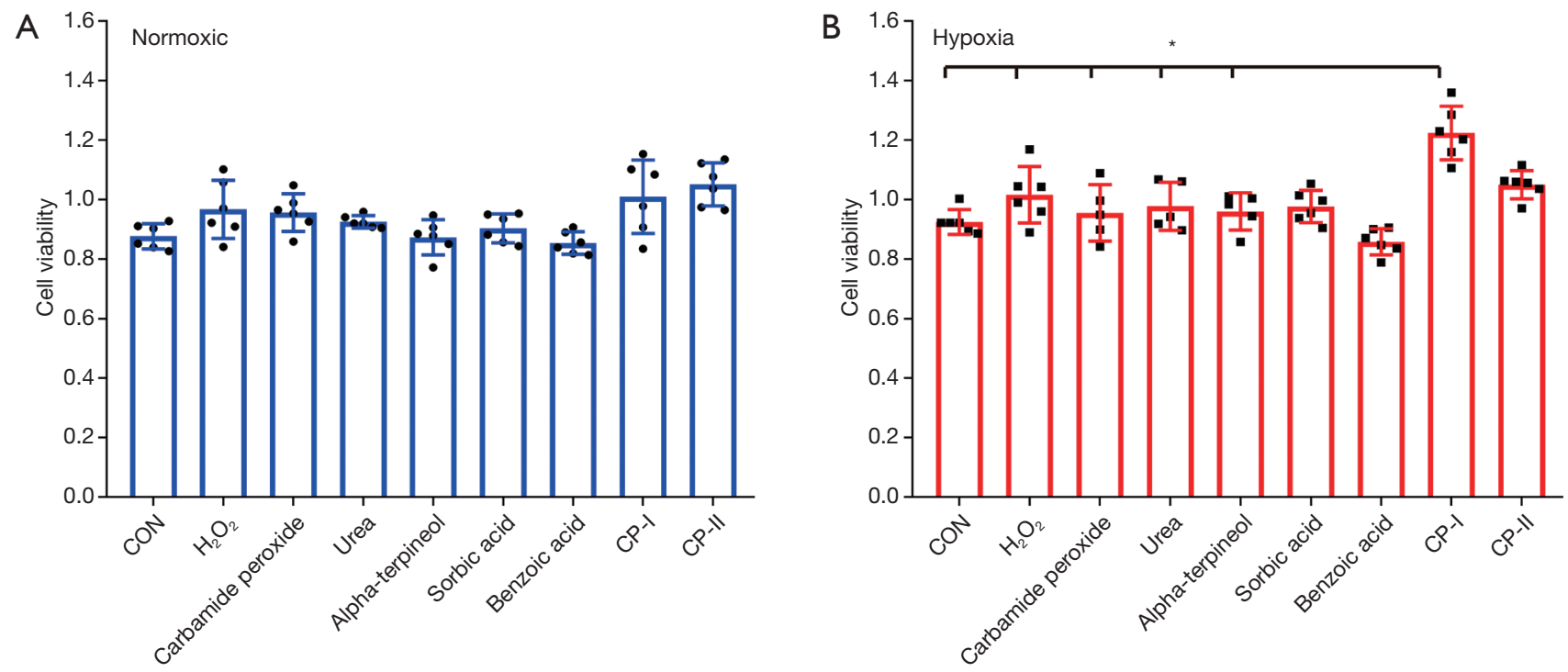

Figure 5 HBMECs were treated with the main components of CP-I and CP-II under normoxic (A) and hypoxic conditions (B) at a concentration of $10 \mu \mathrm{g} \cdot \mathrm{L}^{-1} \cdot \mathrm{n}=6$ vs. control. HBMECs, human brain microvessel endothelial cells; CP, carbamide peroxide. * denotes $\mathrm{P}<0.05$ vs. control.

A
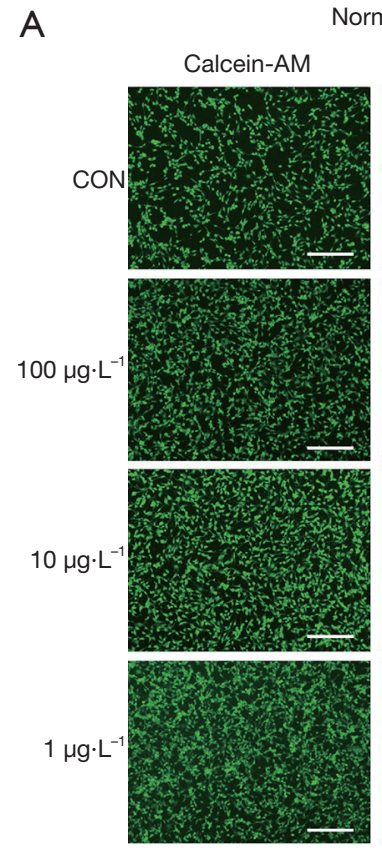

Normoxic
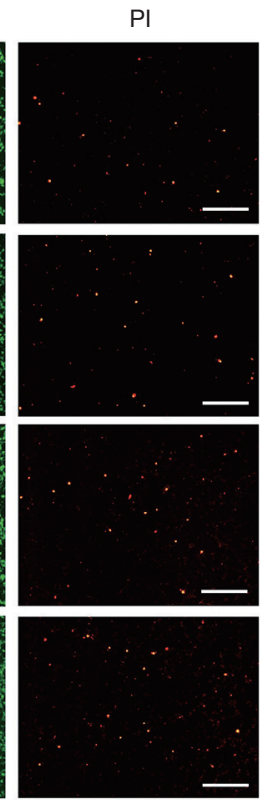

Hypoxia
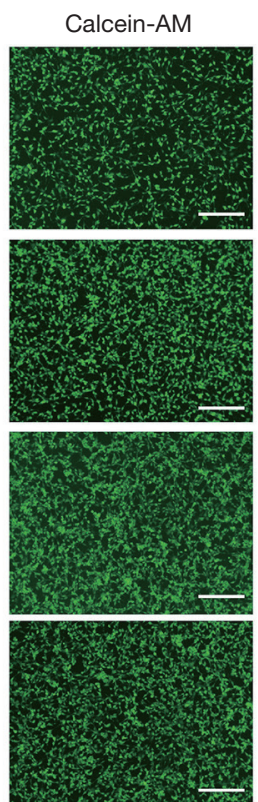

$\mathrm{PI}$
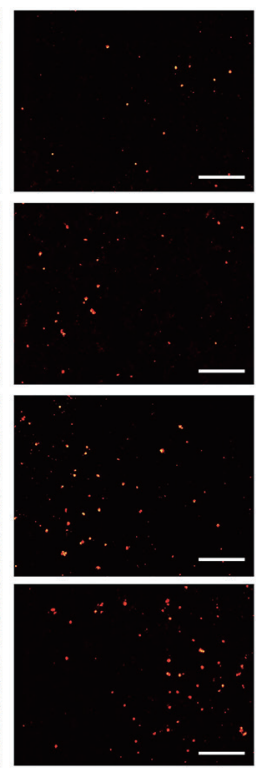
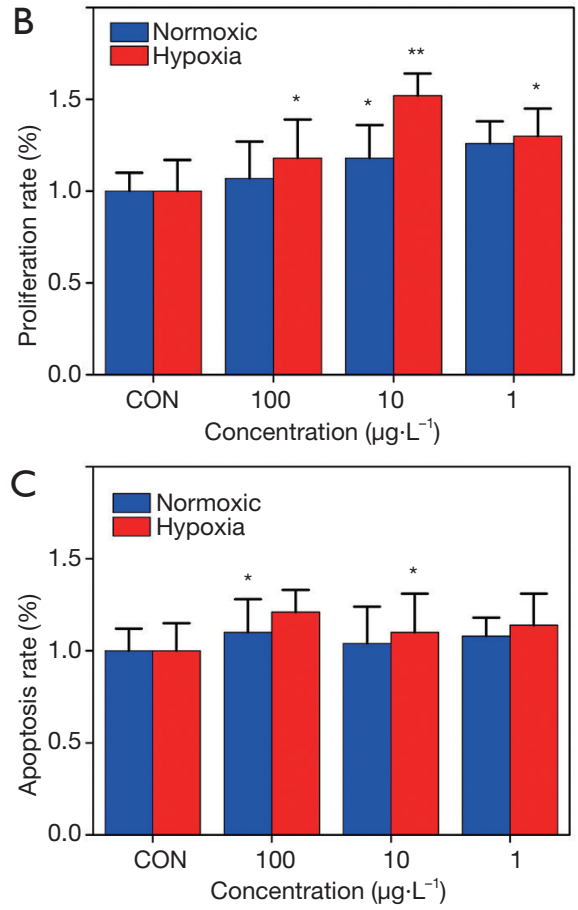

Figure 6 Cells detected by fluorescence microscope after calcein-AM/PI. Fluorescence microscope imaging of HBMECs at different concentrations of CP-I under normoxic and hypoxic conditions (A). Graph showing the rate of proliferation (B) and apoptosis (C) under normoxic and hypoxic conditions. Scale bar $=10 \mu \mathrm{m}$. HBMECs, human brain microvessel endothelial cells; CP, carbamide peroxide. * denotes $\mathrm{P}<0.05$ vs. control; ${ }^{* *}$ denotes $\mathrm{P}<0.01$ vs. control. 
A
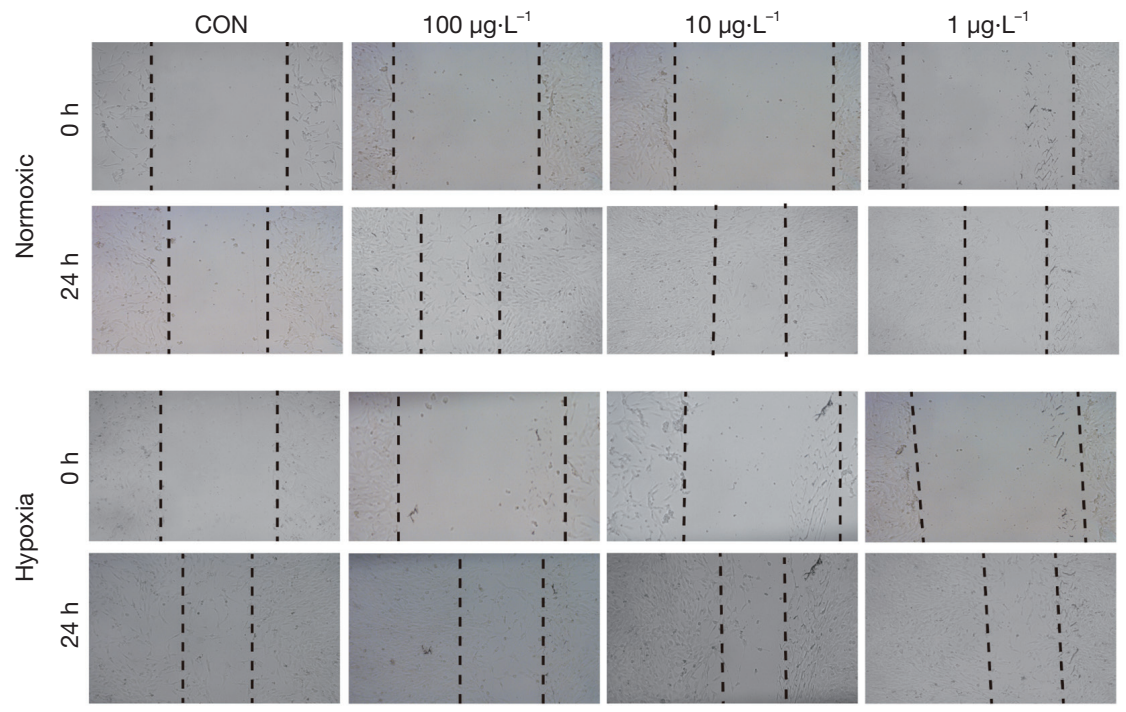

B

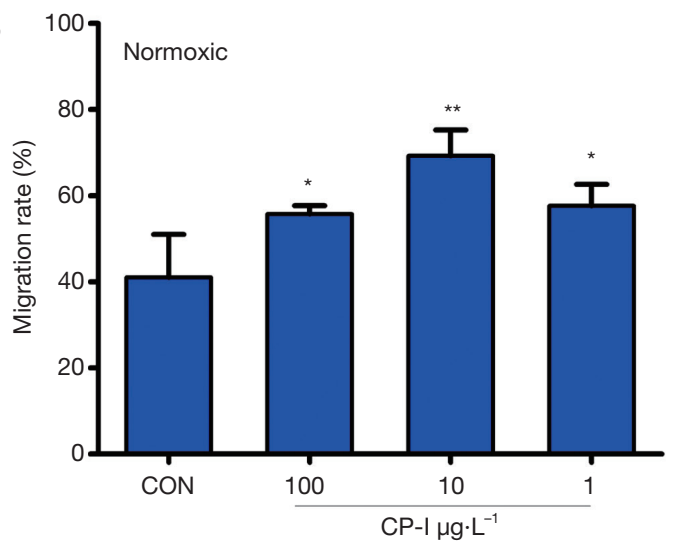

C

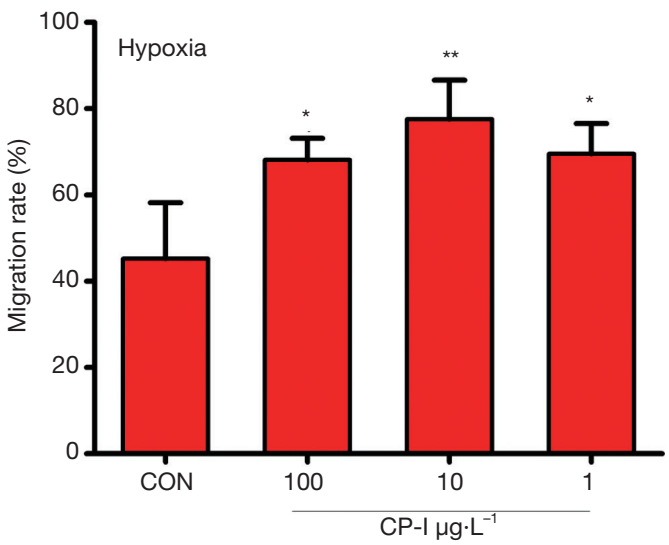

Figure 7 Migration of HBMECs after incubation with different concentrations of CP-I (A) solution $(\times 100)$. Graph showing the rate of migration under normoxic (B) and hypoxic $(\mathrm{C})$ conditions. * denotes $\mathrm{P}<0.05$ vs. control; ${ }^{* *}$ denotes $\mathrm{P}<0.01$ vs. control; $\mathrm{n}=6$. HBMECs, human brain microvessel endothelial cells; CP, carbamide peroxide.

rate and migration ability of HBMECs under hypoxia were evaluated. We chose two different additives for the exploration of the oxygen production rate and oxygen production of CP. The obtained CPs were in solid crystal form, and had advantages of being simple to prepare, easy to use, and suited for large-scale preparation. We used spectrophotometry, oxygen electrode test, and indicator titration for testing the oxygen production rate and oxygen production. The results indicate that alpha-terpineol is the best additive. At low concentrations, CP-I and CP-II have outstanding biocompatibility. Under hypoxic conditions, $\mathrm{CP}$, especially CP-I, acts as an energy replenisher and oxygen supplier to promote cell proliferation and migration. The safety of CP to cells was further verified by calcein-
AM/PI staining. We believe that this completely watersoluble CP (CP-I) opens up new avenues of treatment for the repair of cerebral vascular injury. However, this study is still at the in vitro research stage, and the mechanism of action has not been well elucidated. More detailed and large-scale studies are required in the future.

\section{Acknowledgments}

Funding: This study was supported by the Program of National Natural Science Foundation of China (81870042, 81900050 and 81700045), National Science and Technology Information System of the People's Republic of China (2018YFC1313603) and the Program of Natural Science 
Foundation of Shanghai (18ZR1431500).

\section{Footnote}

Reporting Checklist: The authors have completed the MDAR reporting checklist. Available at http://dx.doi. org/10.21037/atm-20-8137

Data Sharing Statement: Available at http://dx.doi. org/10.21037/atm-20-8137

Conflicts of Interest: All authors have completed the ICMJE uniform disclosure form (available at http://dx.doi. org/10.21037/atm-20-8137). The authors have no conflicts of interest to declare.

Ethical Statement: The authors are accountable for all aspects of the work in ensuring that questions related to the accuracy or integrity of any part of the work are appropriately investigated and resolved.

Open Access Statement: This is an Open Access article distributed in accordance with the Creative Commons Attribution-NonCommercial-NoDerivs 4.0 International License (CC BY-NC-ND 4.0), which permits the noncommercial replication and distribution of the article with the strict proviso that no changes or edits are made and the original work is properly cited (including links to both the formal publication through the relevant DOI and the license). See: https://creativecommons.org/licenses/by-nc-nd/4.0/.

\section{References}

1. Bülow CV, Hayen W, Hartmann A, et al. Endothelial capillaries chemotactically attract tumour cells. J Pathol 2001;193:367-76.

2. Francisco FK, Nikolas O, Ulrich D, et al. Pericytes in capillaries are contractile in vivo, but arterioles mediate functional hyperemia in the mouse brain. Proc Natl Acad Sci USA 2010;107:22290-5.

3. Faropoulos K, Chroni E, Assimakopoulos SF, et al. Altered occludin expression in brain capillaries induced by obstructive jaundice in rats. Brain RES 2010;1325:121-7.

4. Mikeli A, Mario P. A diffusion-consumption problem for oxygen in a living tissue perfused by capillaries. NoDEA 2006;13:349-67.

5. Lin BX, Lu XL, Li N, et al. Effect of Dai-Bai-Jie on the proliferation and migration of the A549 cells. Chin Chem
Lett 2020;31:476-8.

6. Helms HC, Abbott NJ, Burek M, et al. In vitro models of the blood-brain barrier: An overview of commonly used brain endothelial cell culture models and guidelines for their use. J Cereb Blood Flow Metab 2016;36:862-90.

7. Ahmad AA, Gassmann M, Ogunshola OO. Involvement of oxidative stress in hypoxia-induced blood-brain barrier breakdown. Microvasc Res 2012;84:222-5.

8. Laksitorin MD, Yathindranath V, Xiong $\mathrm{W}$, et al. Modulation of $\mathrm{Wnt} /$ beta-catenin signaling promotes blood-brain barrier phenotype in cultured brain endothelial cells. Sci Rep 2019;9:19718.

9. Zhong J, Chen XM, Zhang MR, et al. Blood compatible heteratom-doped carbon dots for bio-imaging of human umbilical vein endothelial cells. Chin Chem Lett 2020;31:769-73.

10. Li Z, Liu T, Long JM, et al. The toxicity of hydroxylated and carboxylated multi-walled carbon nanotubes to human endothelial cells was not exacerbated by ER stress inducer. Chin Chem Lett 2019;30:582-6.

11. Liu YC, Tsai YH, Tang SC, et al. Cytokine MIF Enhances Blood-Brain Barrier Permeability: Impact for Therapy in Ischemic Stroke. Sci Rep 2018;8:743.

12. Wang J, Chen Y, Yang Y, et al. Endothelial Progenitor Cells and Neural Progenitor Cells Synergistically Protect Cerebral Endothelial Cells from Hypoxia/ReoxygenationInduced Injury via Activating the PI3K/Akt Pathway. Mol Brain 2016;9:12.

13. Datta S, Sarvetnick N. Lymphocyte proliferation in immune-mediated diseases. Trends Immunol 2009;30:430-8.

14. Noberini R, Pasquale EB. Proliferation and tumor suppression: not mutually exclusive for Eph receptors. Cancer Cell 2009;16:452-4.

15. Paik JH, Ding Z, Narurkar R, et al. FoxOs cooperatively regulate diverse pathways governing neural stem cell homeostasis. Cell Stem Cell 2009;5:540-53.

16. Hubbi ME, Semenza GL. Regulation of cell proliferation by hypoxia-inducible factors. Am J Physiol-Cell Physiol 2015;309:C775-82.

17. Lee J, Jeon H, Haidar A, et al. Recombinant Phage Coated 1D Al2O3 Nanostructures for Controlling the Adhesion and Proliferation of Endothelial Cells. Biomed Res Int 2015;2015:909807.

18. Lei QS, Zuo YH, Lai CZ, et al. New C 21 steroidal glycosides from the roots of Cynanchum stauntonii and their protective effects on hypoxia/reoxygenation induced cardiomyocyte injury. Chin Chem Lett 2017;28:1716-22. 
19. Yu LD, Chen Y, Chen HR. H2O2-responsive theranostic nanomedicine. Chin Chem Lett 2017;28:1841-50.

20. Sun J, Liu C. Correlation of vascular endothelial function and coagulation factors with renal function and inflammatory factors in patients with diabetic nephropathy. Exp Ther Med 2018;16:4167-71.

21. Tang XH, Xie MA, Peng D. Study on optimization technology condition and stability of urea peroxide. Appl Chem Ind 2009;38:233-9.

22. Tan SZ, Li ZQ. Study on the Synthesis of Urea Peroxide. Chem World 2004;45:644-6.

23. Wang Y, Huang Pu HJ. Study on the synthetic and analytical method for urea peroxide. Appl Chem Ind 2006;35:691-3.

24. Cao JL, Li MQ, Tan ZY, et al. Synthesis of Solid Disinfectant Urea Peroxide by Hydro-processes. Chin J Process Eng 2005;5:517-20.

25. Cao JL, Jing HY, Lan TY, et al. Phase Diagrams of $\mathrm{Na} 2 \mathrm{CO} 3-\mathrm{CO}(\mathrm{NH} 2) 2-\mathrm{H} 2 \mathrm{O} 2-\mathrm{H} 2 \mathrm{O}$ System at $0{ }^{\circ} \mathrm{C}$ and $25^{\circ} \mathrm{C}$ and the Production of Urea Peroxide and Sodium Percarbonate. J Chem Eng Data 2013;58:377-82.

26. Sulieman M. An Overview of Bleaching Techniques: 1. History, Chemistry, Safety and Legal Aspects. Dent Update 2004;31:608-16.

27. Kaewpinta A, Khongkhunthian S, Chaijareenont P, et al. Tooth whitening efficacy of pigmented rice gels containing carbamide peroxide. Drug Discov Ther 2018;12:126-32.

28. Hasegawa H, Tomiyama K, Kumada H, et al. Antimicrobial effects of carbamide peroxide against a polymicrobial biofilm model. Am J Dent 2015;28:57-60.

29. Xu JJ, Xiao CH, Ding SJ. Red-blood-cell like nitrogendoped carbons with highly catalytic activity towards oxygen reduction reaction. Chin Chem Lett 2017;28:748-54.

30. Wang YM, Luo EG, Wang X, et al. Fe, Cu-codoped metal-nitrogen-carbon catalysts with high selectivity and stability for the oxygen reduction reaction. Chin Chem Lett 2020;559:1-5.

31. Wen Y, Huo FJ, Yin CX. Organelle targetable fluorescent probes for hydrogen peroxide. Chin Chem Lett 2019;30:1834-42.

32. Mustafa A, Amir R, Ganjali MR. High performance electrode material for supercapacitors based on $\alpha-\mathrm{Co}(\mathrm{OH}) 2$ nano-sheets prepared through pulse current cathodic electro-deposition (PC-CED). Electron Mater Lett 2018;14:37-45.

33. Kumarasinghe AR, Samaranayake L, Bondino F, et al. Self-Assembled Multilayer Graphene Oxide Membrane and Carbon Nanotubes Synthesized Using a Rare Form of
Natural Graphite. J Phys Chem C 2013;117:9507-19.

34. Seymour TA, Li JS, Morrissey MT. Characterization of a Natural Antioxidant from Shrimp Shell Waste. J Agric Food Chem 1996;44:682-5.

35. Netai MM, Kugara J, Zaranyika MF. Surface composition and surface properties of water hyacinth (Eichhornia crassipes) root biomass: Effect of mineral acid and organic solvent treatment. Afr J Biotechnol 2016;15:891-6.

36. Coates JP. The Interpretation of Infrared Spectra: Published Reference Sources. Appl Spectrosc Rev 1996;31:179-92.

37. Lundstr A, Andersson B, Olsson L. Urea thermolysis studied under flow reactor conditions using DSC and FTIR. Chem Eng J 2009; 150:544-50.

38. Linares M, Alexander B. Solid-state synthesis of headto-tail photodimers from supramolecular assemblies directed by charge-assisted hydrogen bonds. New J Chem 2010;34:587-90.

39. Wang Y, Jiang GH, Zhang M, et al. Facile one-pot preparation of novel shell cross-linked nanocapsules: inverse miniemulsion RAFT polymerization as an alternative approach. Soft Matter 2011;7:5348.

40. Franco DL, Afonso AS, Vieira SN, et al. Electropolymerization of 3-aminophenol on carbon graphite surface: Electric and morphologic properties. Mater Chem Phys 2008;107:404-9.

41. Wang XS, Zeng JY, Zhang MK, et al. A Versatile Pt-Based Core-Shell Nanoplatform as a Nanofactory for Enhanced Tumor Therapy. Adv Funct Mater 2018. doi: 10.1002/ adfm.201801783.

42. Wei JP, Li JC, Sun D, et al. A Novel Theranostic Nanoplatform Based on Pd@Pt-PEG-Ce6 for Enhanced Photodynamic Therapy by Modulating Tumor Hypoxia Microenvironment. Adv Funct Mater 2018. doi: 10.1002/ adfm.201706310.

43. Hanks CT, Fat JC, Wataha JC, et al. Cytotoxicity and Dentin Permeability of Carbamide Peroxide and Hydrogen Peroxide Vital Bleaching Materials, in vitro. J Dent Res 1993;72:931-8.

44. Soares DG, Ribeiro AP, Lima AF, et al. Effect of fluoride-treated enamel on indirect cytotoxicity of a $16 \%$ carbamide peroxide bleaching gel to pulp cells. Braz Dent J 2013;24:121-7.

45. Sinensky MC, Leiser AL, Babich H. Oxidative stress aspects of the cytotoxicity of carbamide peroxide: in vitro studies. Toxicol Lett 1995;75:101-9.

46. Lima AF, Ribeiro APD, Soares DGS, et al. Toxic effects of daily applications of $10 \%$ carbamide peroxide on 
odontoblast-like MDPC-23 cells. Acta Odontol Scand 2013;71:1319-25.

47. Cardoso PC, Reis A, Loguercio A, et al. Clinical Effectiveness and Tooth Sensitivity Associated With Different Bleaching Times for a 10 Percent Carbamide Peroxide Gel. J Am Dent Assoc 2010;141:1213-20.

48. de Castro Albuquerque R, Gomez RS, Dutra RA, et al. Effects of a $10 \%$ carbamide peroxide bleaching agent on rat oral epithelium proliferation. Braz Dent J 2002;13:162-5.

49. Mazin PV, Shagimardanova E, Kozlova O, et al. Cooption of heat shock regulatory system for anhydrobiosis in the sleeping chironomid Polypedilum vanderplanki. Proc Natl Acad Sci U S A 2018;115:E2477-86.

50. Hanagata N, Zhuang F, Connolly S, et al. Molecular responses of human lung epithelial cells to the toxicity of copper oxide nanoparticles inferred from whole genome expression analysis. ACS Nano 2011;5:9326-38.

51. Fang X, Huang T, Zhu Y, et al. Connexin 43 hemichannels contribute to cadmium-induced oxidative stress and cell injury. Antioxid Redox Signal 2011;14:2427-39.

52. Wang $X, \mathrm{Li} X$, Ito $\mathrm{A}$, et al. Synthesis and characterization of hierarchically macroporous and mesoporous $\mathrm{CaO}-\mathrm{MO}-$ $\mathrm{SiO}(2)-\mathrm{P}(2) \mathrm{O}(5)(\mathrm{M}=\mathrm{Mg}, \mathrm{Zn}, \mathrm{Sr})$ bioactive glass scaffolds. Acta Biomater 2011;7:3638-44.

53. Sato N, Yamabuki T, Takano A, et al. Wnt inhibitor Dickkopf-1 as a target for passive cancer immunotherapy. Cancer Res 2010;70:5326-36.

(English Language Editor: J. Gray)
Cite this article as: Meng X, Sun Y, Wang L, Li Y, Ouyang R, Yuan P, Miao Y. Slow release of oxygen from carbamide peroxide for promoting the proliferation of human brain microvascular endothelial cells under hypoxia. Ann Transl Med 2021;9(2):157. doi: 10.21037/atm-20-8137 


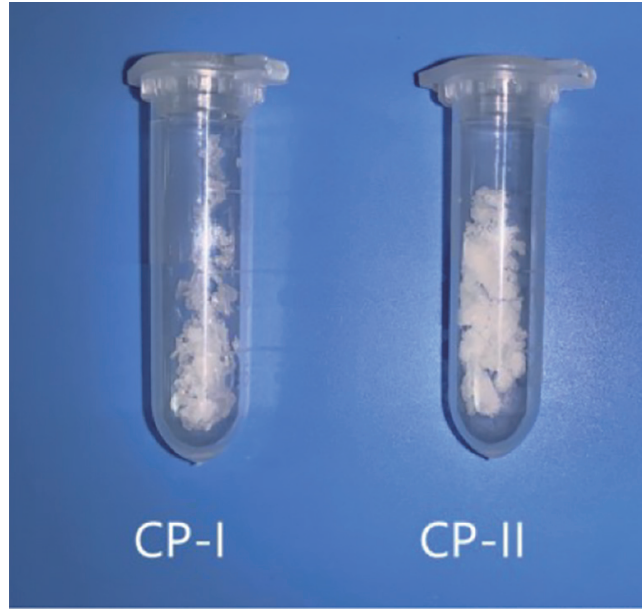

Figure S1 A digital photo of CP-I and CP-II crystals. CP, carbamide peroxide.

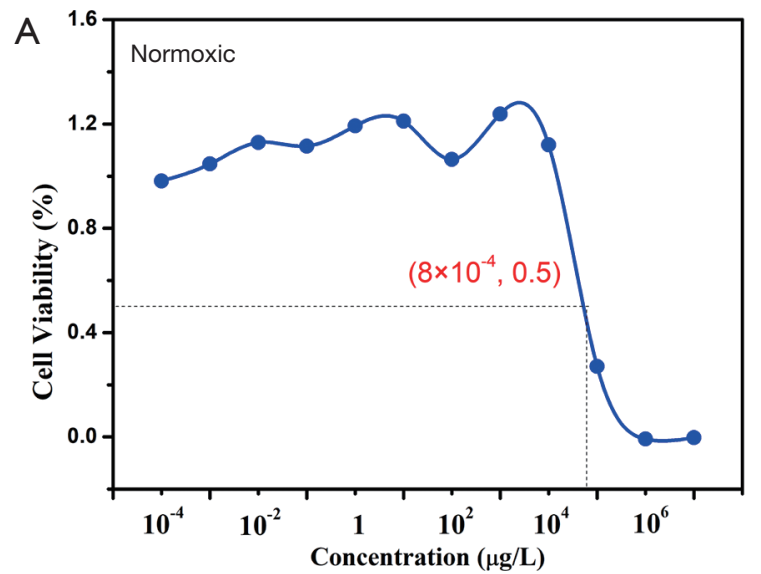

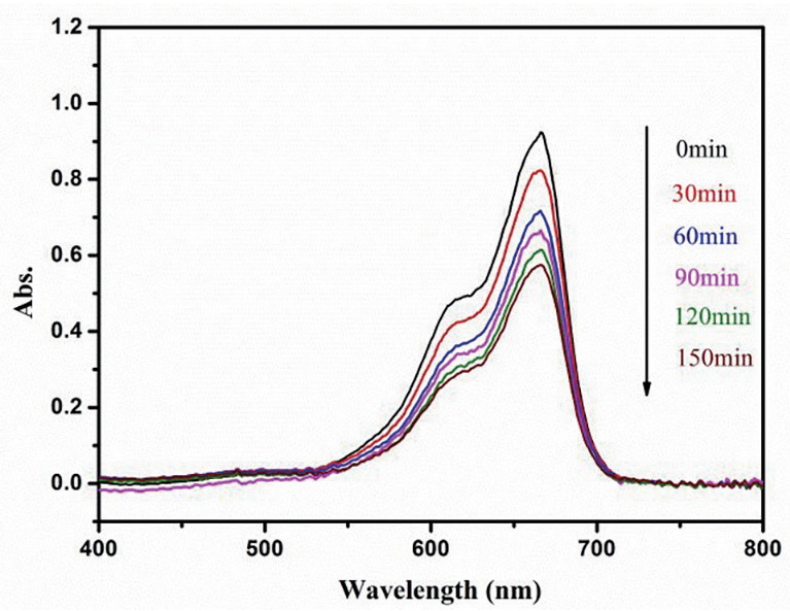

Figure S2 UV-vis absorption spectra of $10 \mathrm{mg} \cdot \mathrm{mL}^{-1} \mathrm{CP}-\mathrm{II}$ in $0.15 \mathrm{mmol} \cdot \mathrm{L}^{-1}$ of methylene blue solution. $\mathrm{CP}$, carbamide peroxide.

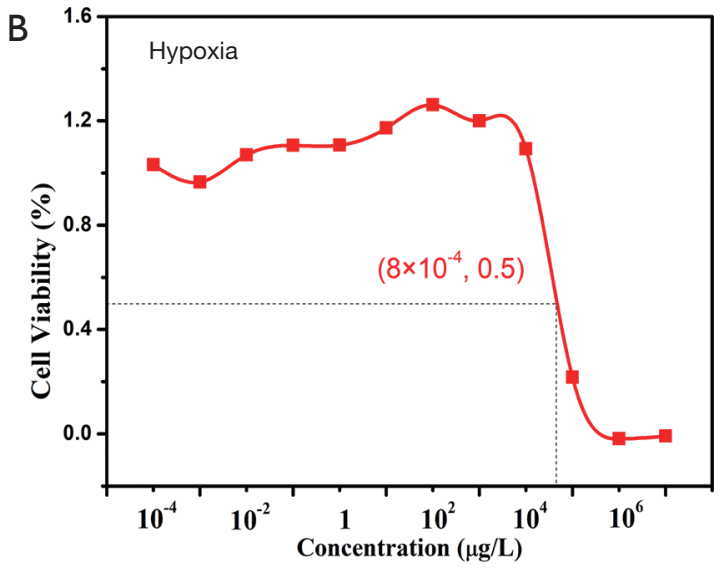

Figure S3 Cytotoxicity test of CP-II (A,B) under normoxic and hypoxic conditions. CP, carbamide peroxide. 